\title{
In situ thermal excursions detected in the Nankai Trough forearc slope sediment at IODP NanTroSEIZE Site C0008
}

\author{
Masataka Kinoshita ${ }^{1 *}$, Hiroaki Fukase ${ }^{2}$, Shusaku Goto ${ }^{3}$ and Tomohiro Toki ${ }^{4}$
}

\begin{abstract}
At Integrated Ocean Drilling Program (IODP) Site C0008 in the Nankai Trough slope sediment, we discovered in situ temperature anomalies at 80 to $160 \mathrm{~m}$ below the seafloor, where pore fluid $\mathrm{Cl}$ and $\delta^{18} \mathrm{O}$ excursions were identified and interpreted as pore fluid refreshing due to hydrate dissociation. The volume fraction of hydrates is estimated to be approximately 3\% and approximately 40\% maximum at Holes C0008A and C0008C, respectively. In the vicinity of these anomalies, we discovered negative and positive temperature excursions of up to $1 \mathrm{~K}$ measured in situ using the Advanced Piston Corer Temperature (APC-T) tool attached to the shoe of a hydraulic piston corer. They are significantly larger than the uncertainties caused during data acquisition and processing. Frictional heat due to penetration increased the temperature by $>10 \mathrm{~K}$, exceeding the gas/hydrate stability temperature at that depth. This heat is partly consumed by hydrate dissociation, which disturbs the thermal decay curve after penetration, but 2D numerical modeling revealed that hydrate dissociation does not significantly change the extrapolated equilibrium temperature. So far, we cannot suggest any acceptable explanation for the observed thermal anomalies, although we strongly suspect that it is related to hydrate dissociation.
\end{abstract}

Keywords: NanTroSEIZE; Methane hydrate; Endothermic; Friction

\section{Findings}

\section{Introduction}

The Nankai Trough forearc system forms an active subduction complex overlying a seismogenic zone of great earthquakes and tsunamis. As part of the Integrated Ocean Drilling Program (IODP) Nankai Trough Seismogenic Zone Experiments (NanTroSEIZE; e.g., Tobin and Kinoshita 2006), shallow holes were drilled at Site C0008 on the slope sediment $1 \mathrm{~km}$ seaward of Site C0004, penetrating the mega-splay fault (Figure 1), in order to characterize the lithological features and history of the slope sediment near shallow faults (Expedition 316 Scientists, 2009). Holes C0008A and C0008C were cored to 270 and 190 meters below the seafloor (mbsf), respectively.

Bottom-simulating reflectors (BSRs) that mark the top of the free gas zone beneath the hydrate stability zone are intermittently identified in the slope sediment or

\footnotetext{
* Correspondence: masa@jamstec.go.jp

${ }^{1}$ Kochi Institute for Core Sample Research of JAMSTEC, Nankoku, Kochi 783-8502, Japan

Full list of author information is available at the end of the article
}

accretionary prism (e.g., Kinoshita et al. 2011). The lack of BSRs does not necessarily mean the absence of gas or hydrates in the formation. Ashi et al. (2002) explain that seismically identifiable BSRs are not formed during active geological processes such as rapid sedimentation or subsidence, because of insufficient gas to form hydrates at the new (moving) gas and hydrate stability boundary.

Although no BSRs are seen below Site C0008, some scattered negative excursions in chlorinity $(\mathrm{Cl})$ and positive excursions in oxygen isotope ratio $\left(\delta^{18} \mathrm{O}\right)$ were reported from the pore fluid squeezed from core samples taken from 80 to 160 mbsf (Expedition 316 Scientists, 2009). In the vicinity of these anomalies, we discovered some temperature excursions measured in situ using the Advanced Piston Corer Temperature (APC-T) tool attached to the shoe of a hydraulic piston corer.

We carefully examine these anomalies and discuss their possible causes. Hydrate saturation is first estimated from $\mathrm{Cl}$ and $\delta^{18} \mathrm{O}$ anomalies. Then, we examine the quality of temperature data by searching for some critical parameters, i.e., the penetration time and time interval 

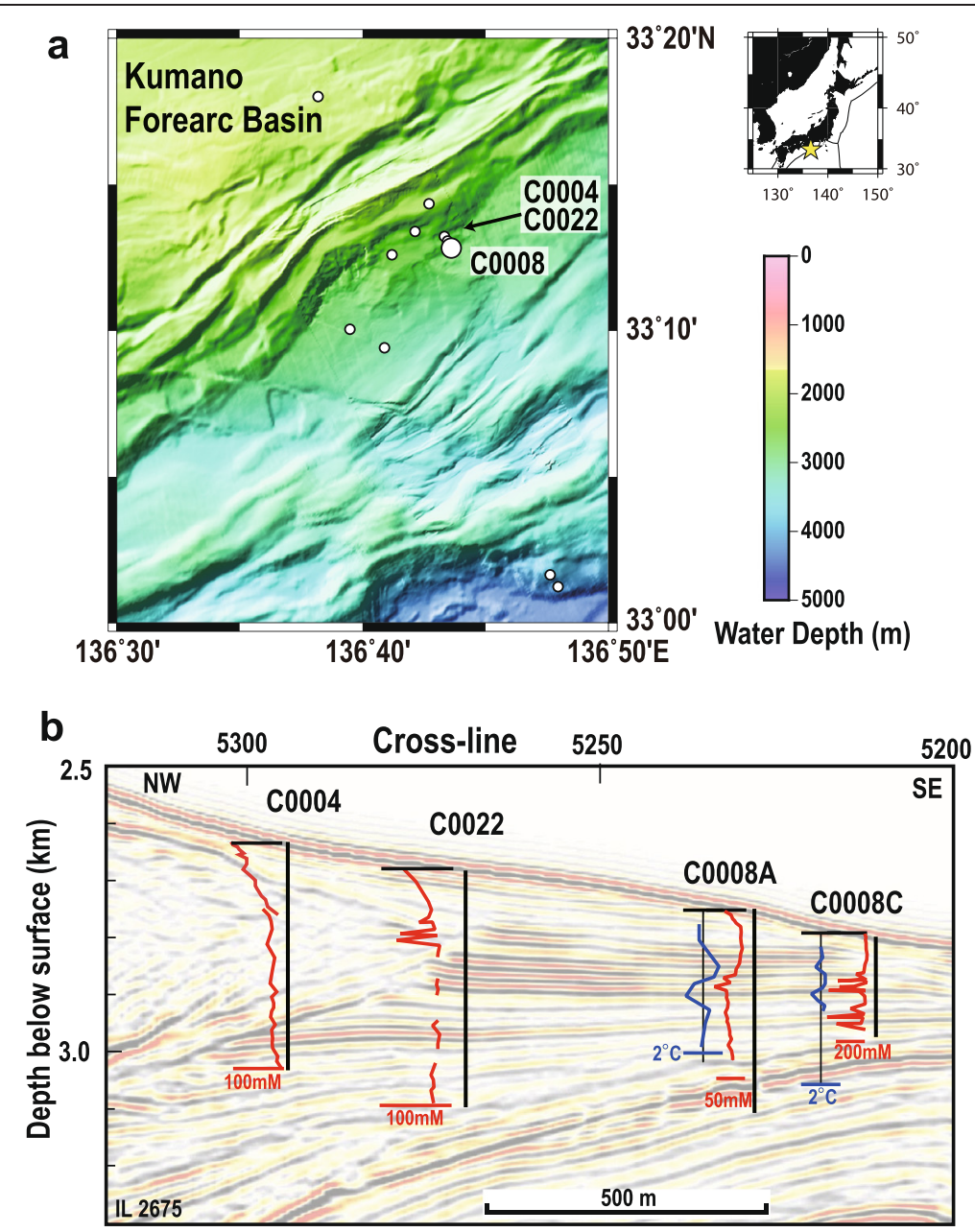

Figure 1 Index map of NanTroSEIZE Site C0008 and seismic section around Sites C0004, C0008, and C0022. (a) Index map showing the location of NanTroSEIZE Site C0008 in the forearc slope of the Nankai Trough off Kii Peninsula, Japan. Small circles are the other drill sites. (b) Seismic section around Sites C0004, C0008, and C0022 (Moore et al. 2013). Residual temperatures (blue) and Cl anomalies (red) are plotted alongside each site.

used for extrapolation. Then, we explore the possible relationship between thermal excursion and dissociation of gas hydrates upon penetration.

\section{Lithostratigraphy at Site $\mathrm{C0008}$}

At Site C0008, the slope basin sediment is located at the footwall side of the splay fault. Strasser et al. (2011) and Kimura et al. (2011) interpreted its lithostratigraphy as consisting of three sedimentary units, based on 3D seismic data and Expedition 316 Scientists (2009) (Figure 1). The topmost unit 1a is composed of silty mud and turbidites. The underlying unit $1 \mathrm{~b}$ consists of abundant coarse turbidite and ash layers with mud beds. Unit $1 \mathrm{c}$ is dominated by silty clay with beds of sand to silt, underlain by 40-m-thick mass transport deposits (MTDs) (Strasser et al. 2011). Beneath unit $1 \mathrm{c}$ is the older accretionary prism, composed of fine- to coarse-grained sandstone, interpreted as trench-wedge turbidites.

\section{$\mathrm{Cl}$ and $\delta^{18} \mathrm{O}$ excursions}

Chemical analyses were carried out on pore fluid squeezed from core samples (Expedition 316 Scientists, 2009). Negative excursions from the baseline trend of the $\mathrm{Cl}$ concentration curve were observed in the interstitial water taken from core samples (Expedition 316 Scientists, 2009). At Hole C0008A, two negative $\mathrm{Cl}$ excursions (552 and $536 \mathrm{mM}$ ) were detected at 120.3 and $136.3 \mathrm{mbsf}$, respectively (Figure 2). At Hole C0008C, pronounced negative $\mathrm{Cl}$ excursions were observed at $73,86,95,96,102,135,150$, 161 , and 167 mbsf (minimum value $=293 \mathrm{mM}$ ). These negative $\mathrm{Cl}$ excursions likely reflect pore fluid freshening because of the dissociation of gas hydrates when the core samples that include hydrates are recovered (Expedition 316 Scientists, 2009). The sampled gas hydrate-bearing horizons are associated with ash and coarse-grained sand layers.

Similarly, when gas hydrates are formed, heavier $\mathrm{H}_{2}^{18} \mathrm{O}$ is preferentially incorporated in the hydrate structure, 


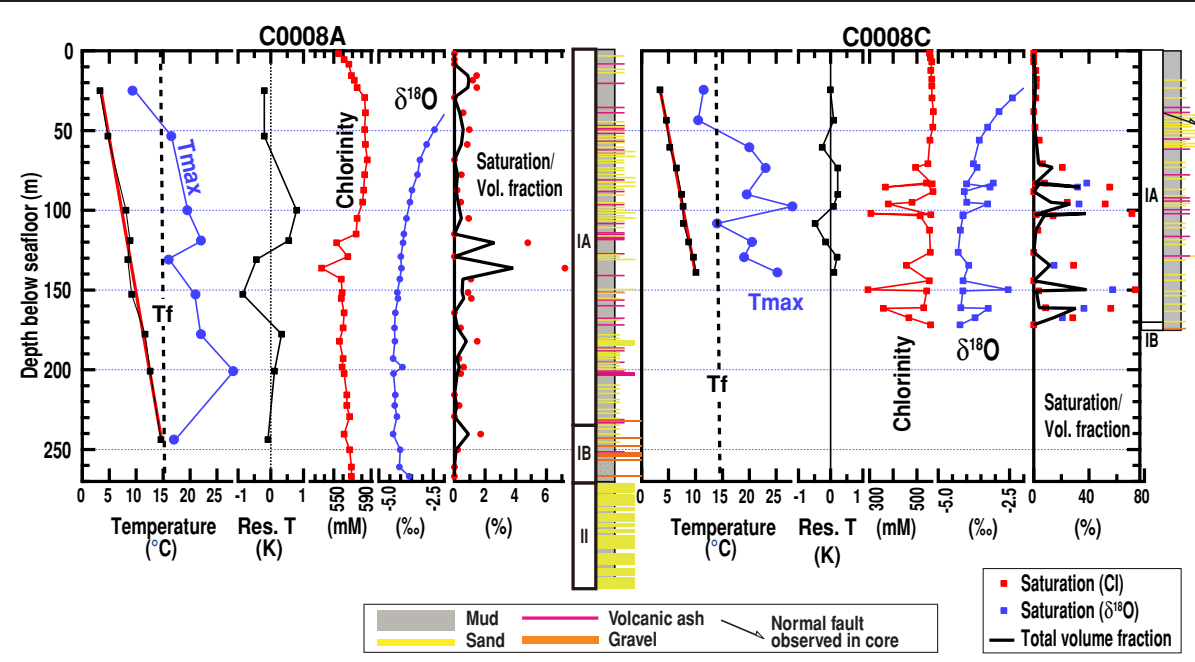

Figure 2 Depth profiles at Holes C0008A and C0008C. (Left to right) In situ temperature (black curve with red best-fit line); maximum recorded temperature during measurements (Tmax) (blue); residual temperature (black); chlorinity (red); $\delta^{18} \mathrm{O}$ isotopic ratio (blue); estimated hydrate saturation (red dots from chlorinity, blue dots from $\delta^{18} \mathrm{O}$ ); total volume fraction estimated from $\mathrm{Cl}$ anomaly (black line) at Holes C0008A and C0008C. Tf (black dashed line): temperature at gas/hydrate phase boundary.

and the pore fluids become depleted of $\delta^{18} \mathrm{O}$. When gas hydrates dissociate, $\mathrm{H}_{2}^{18} \mathrm{O}$ is released back into the pore fluids, and they become enriched in $\delta^{18} \mathrm{O}$ (e.g., Maekawa, 2004). At Hole C0008A, there were no variations in the $\delta^{18} \mathrm{O}$ profile at 120 and $136.3 \mathrm{mbsf}$, where there are anomalies in the $\mathrm{Cl}$ concentration, probably because of low hydrate saturation at C0008A (Expedition 316 Scientists, 2009; Figure 2). In Hole C0008C, on the other hand, there were five positive excursions at $83,86,96,150$, and 161 mbsf of up to $1 \%$, which coincide with intervals of $\mathrm{Cl}$ excursions.

Hydrate saturation estimated from $\mathrm{Cl}$ and $\delta^{18} \mathrm{O}$ anomalies Here, the hydrate saturation and its volume fraction in the sediment are estimated following the method outlined by Matsumoto and Borowski (2000).

The volume fraction of pure water dissociated from hydrate in the squeezed water samples, $M_{\mathrm{Cl}}$, is expressed in terms of the measured $\mathrm{Cl}$ concentration $\mathrm{Cl}_{m}$ and the baseline value $\left(\mathrm{Cl}_{b}\right)$ as:

$$
M_{\mathrm{Cl}}=1-\mathrm{Cl}_{m} / \mathrm{Cl}_{b}
$$

Similarly, $M$ is estimated from the $\delta^{18} \mathrm{O}$ value measured in (mixed) pore water samples, that of the pristine pore water unaffected by gas hydrate dissociation, and the hydrate-water fractionation value or the difference between gas hydrates and ambient water $\left(\delta^{18} \mathrm{O}_{\mathrm{GH}-\mathrm{IW}}\right)$ :

$$
M_{\delta^{18} \mathrm{O}}=1-\left(\delta^{18} \mathrm{O}_{m}-\delta^{18} \mathrm{O}_{b}\right) / \delta^{18} \mathrm{O}_{\mathrm{GH}-\mathrm{IW}}
$$

The hydrate-water fractionation value depends on, among other things, the location and temperature. Here, we use a value of 3.1\% (Tomaru et al. 2004).
Hydrate saturation, $S_{h}$, is the volume fraction of gas hydrates in the sediment pore space calculated from $M$ and the density of the gas hydrate (Matsumoto et al. 2004) as:

$$
S_{h}(\%)=1.27 M /(1+0.27 M) \times 100
$$

where $M$ corresponds to $M_{\mathrm{Cl}}$ for the $\mathrm{Cl}$ anomaly and $M_{\delta^{18} \mathrm{O}}$ for the $\delta^{18} \mathrm{O}$ anomaly.

Finally, the total volume fraction of gas hydrates in the sediment $\left(C_{h}\right)$ is calculated as a product of $S_{h}$ and porosity. Here, we used the porosity measured from nearby core samples (Expedition 316 Scientists, 2009).

Figure 2 shows the depth profiles of $S_{h}$ and $C_{h}$ at Holes C0008A and C0008C. At Hole C0008C, the maximum hydrate saturation is estimated as $73 \%$ (from the $\mathrm{Cl}$ anomaly) and $56 \%$ (from $\delta^{18} \mathrm{O}$ ). Accordingly, the maximum hydrate fraction $\left(C_{h}\right)$ is estimated as $38 \%$ and $29 \%$, respectively. Those in Hole C0008A, however, are much lower, with $S_{h}=6.1 \%$ and $C_{h}=3.2 \%$, although Hole C0008A is located only $200 \mathrm{~m}$ landward of Hole C0008C. These hydratecontaining zones generally coincide with the sanddominant strata (Figures $1 \mathrm{~b}$ and 2).

At Hole C0008C, the saturation estimated from the $\delta^{18} \mathrm{O}$ anomaly is in good agreement with that from the $\mathrm{Cl}$ anomaly, although the former tends to be smaller than the latter. This may result from the uncertainty in the hydrate-water fractionation value of $\delta^{18} \mathrm{O}$, but we do not discuss this topic here.

\section{In situ temperatures determined using APC-T tool}

In situ temperatures were measured at $10-$ to $20-\mathrm{m}$ depth intervals using the APC-T tool in Holes C0008A 
and C0008C (Expedition 316 Scientists, 2009). The bestfit heat flow values are 52 to $55 \mathrm{~mW} / \mathrm{m}^{2}$.

Figure 2 shows in situ temperatures and their residuals from their linear trends vs. depth. The residual temperatures in both holes have some excursions of up to $1 \mathrm{~K}$ at 100 to $120 \mathrm{~m}$ and 130 to $150 \mathrm{~m}$ (C0008A) and approximately $100 \mathrm{~m}(\mathrm{C} 0008 \mathrm{C})$, many of which roughly correspond to the intervals with $\mathrm{Cl}$ and $\delta^{18} \mathrm{O}$ anomalies. However, a closer look reveals that the thermal anomaly intervals are located slightly above and beneath the chemical anomalies. We should note that the measurement intervals are probably too sparse to make a point-topoint comparison. Besides, the thermal anomaly at Hole $\mathrm{C} 0008 \mathrm{C}$ is smaller than that at Hole C0008A, whereas $\mathrm{Cl}$ anomalies are larger at Hole C0008C. In the following sections, we explore the data more carefully and discuss possible causes.

\section{Possible causes for thermal excursions}

Thermal excursions can either be a long-term feature due to thermal refraction or fluid advection, an apparent decrease due to uncertainties or misfit of the data extrapolation, or an endothermic reaction due to gas hydrate dissociation.

In a steady-state one-dimensional thermal conduction regime, the temperature profile becomes nonlinear if the thermal conductivity changes with depth. This nonlinearity is corrected to a linear profile by applying the "Bullard plot', or temperature vs. thermal resistance plot (e.g., Bullard, 1954). At Site C0008, however, the Bullard plots are still nonlinear (Expedition 316 Scientists, 2009), and the thermal excursions remain almost the same, so we discard this possibility.

The temperature profile is disturbed if there is advective fluid flow in the Kumano forearc sediments (e.g., Toki et al. 2014; Yamano et al. 2014). Although we cannot exclude this possibility, it is not likely for negative thermal anomalies because decreasing the temperature would require an input of shallower source fluid in the downward direction, which is difficult under the lithological condition around this site. On the other hand, the positive thermal anomaly at Hole C0008A may be caused by a horizontal fluid flow along sandy horizons (Expedition 316 Scientists, 2009).

If the tool does not have good contact with the formation, drilling fluid or seawater can enter the space, cooling it by $1 \mathrm{~K}$ or more (Shipboard Scientific Party et al. 1992; Pribnow et al. 2000). In that case, the temperaturetime plot is obviously scaled out from the gradual trend toward an equilibrium temperature. All the curves at Site C0008 seem to converge to a point, although some operations were disturbed by multiple penetrations (Expedition 316 Scientists, 2009). We therefore exclude this possibility.

\section{Uncertainty in temperature extrapolation}

In situ temperatures are extrapolated from APC-T measurements for approximately $10 \mathrm{~min}$, using the software 'tpfit3.exe' developed by Heesemann et al. (2006), which includes the 3D-geometry effect and the dependence of the thermal diffusion process on thermal properties (e.g., thermal conductivity).

When the corer is fired into the formation, the temperature around the shoe abruptly increases because of frictional heating. This is followed by a gradual approach toward an in situ value (Figure 3). Although the accuracy of the sensor itself is a few $10 \mathrm{mK}$, there is always an uncertainty in the estimated in situ temperatures because the measurement time is shorter than the time needed to come to complete thermal equilibrium, and many processes (possible sources of disturbance) related to the penetration and formation thermal properties remain unknown. Even when very high-quality data is collected, ambiguities in processing generally result in uncertainties in equilibrium temperatures on the order of $0.1^{\circ} \mathrm{C}$ to $0.2^{\circ} \mathrm{C}$ (Heesemann et al. 2006).

Heesemann et al. (2006) report that the exact tool penetration time is virtually impossible to predict $a$ priori. This is because the actual penetration (and thus the frictional heating) occurs in a complicated way, whereas the model assumes instantaneous frictional heating. Practically, the time shift relative to the penetration is statistically determined to minimize the misfit between measurements and the model. Figure 4 shows extrapolated temperatures (Teq) and their standard deviations vs. time shift for all APC-T operations in Hole C0008A. Thick curves correspond to cases with thermal anomalies. From Figure 4, the dependence of Teq on the time shift is estimated as 0.02 to $0.03 \mathrm{~K} / \mathrm{s}$, and the uncertainty in the time shift is less than approximately $10 \mathrm{~s}$. Thus, we estimate that the uncertainties in extrapolated temperature with respect to the time shift are less than 0.2 to $0.3 \mathrm{~K}$.

The selection of time interval (t_st and t_fi in Figure 3) used to estimate Teq also causes uncertainties. Sometimes, there are step changes or other variations due to movement of the tool or the surrounding sediment/water. Some operations in Hole C0008A showed multiple temperature spikes, suggesting multiple penetrations (Expedition 316 Scientists, 2009). Upon processing, they are excluded from the data regression, but such disturbances can remain in the subsequent data, affecting the estimation. Besides, the selection of time intervals by eye can result in somewhat arbitrary time intervals, depending on the operation. If the penetration is made ideally, we empirically know that Teq does not depend on the selected time interval, but there are cases where Teq varies with the selection of time interval.

Therefore, we reprocessed the data by selecting the same interval (approximately 60 to $400 \mathrm{~s}$ after penetration) as 

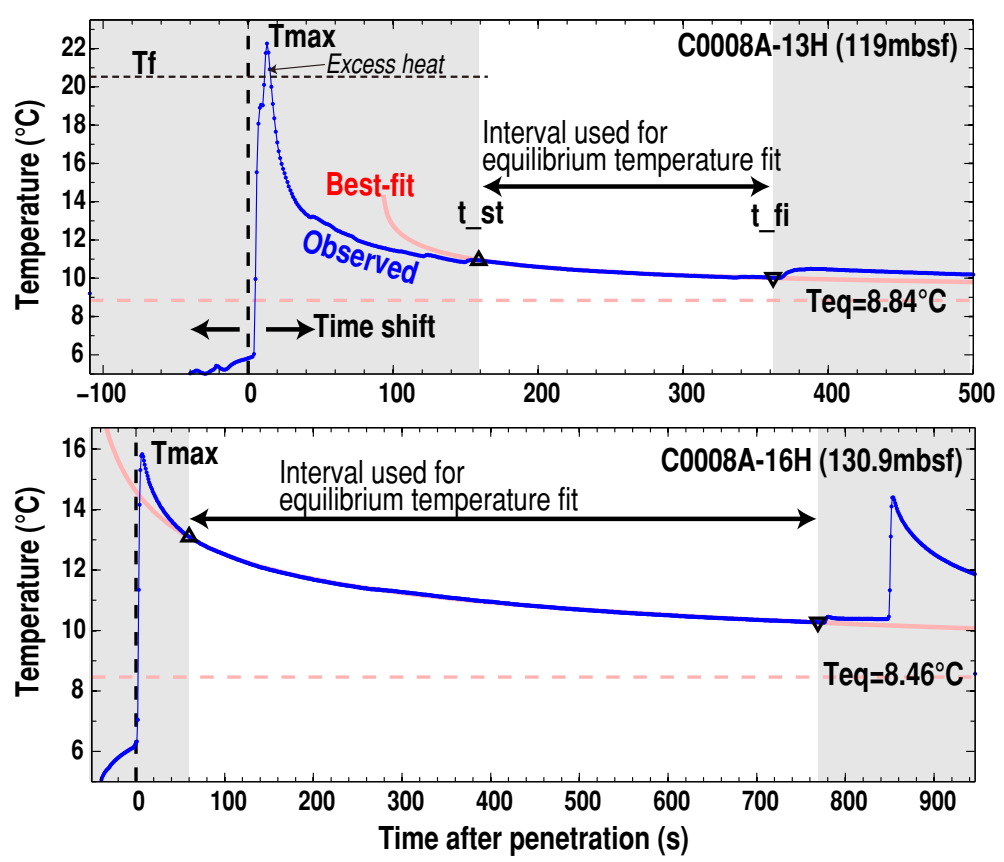

Figure 3 Examples of temperature measurements and extrapolation at Hole C0008A. Top: 119 mbsf (13H). Bottom: 130.9 mbsf (16H) (modified from Expedition 316 Scientists, 2009). t_st and t_fi: first and last data points used for equilibrium temperature fit.

much as possible for all operations and by manually selecting a 'clean' interval as for long as possible. These two cases should provide some sense of overall reliability to Teq. Figure 5 shows reprocessed temperature vs. depth profiles for Hole C0008A. Although the differences are large at 119 and 130.9 mbsf, we still see a clear negative excursion.

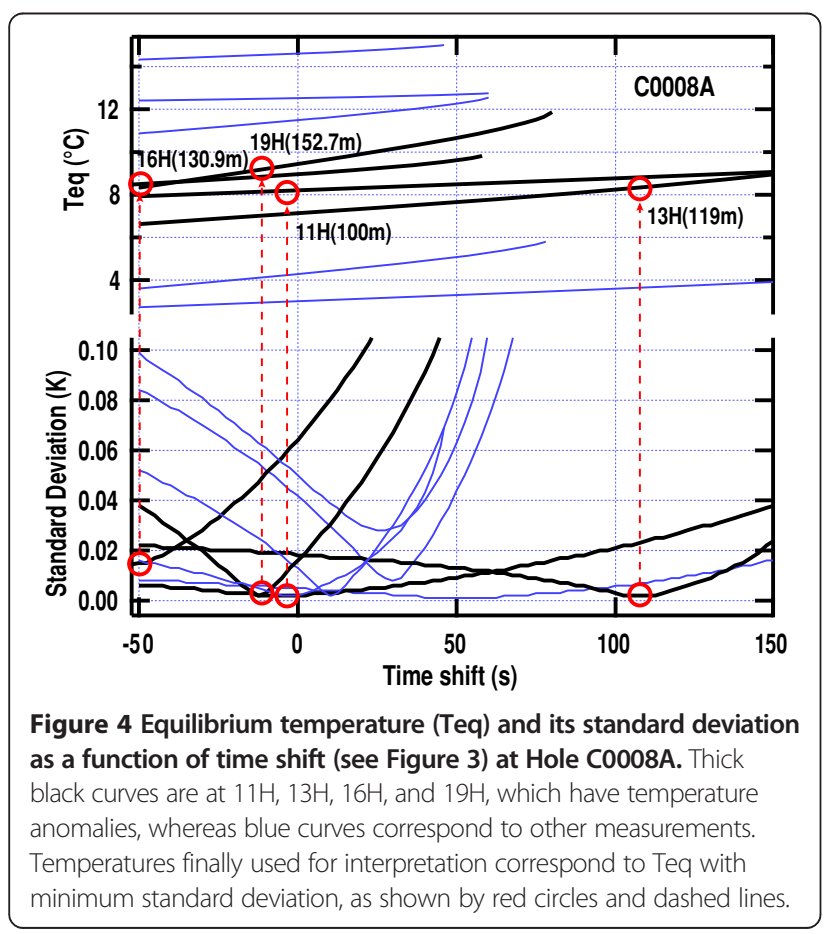

We conclude that thermal excursions of up to $1 \mathrm{~K}$ are significantly larger than the processing errors due to nonideal penetrations or to uncertainties caused by an arbitrary selection of time intervals.

\section{Dissociation of gas hydrates}

Here, we focus on the possible causes for negative thermal excursions. Drilled intervals at both holes are in the hydrate stability zone. When gas hydrates are decomposed into gas and water, thermal energy in the sediment is consumed as latent heat. This may result in a temperature decrease from the original state. Besides, the fresh water dissociated from the hydrates will reduce the chlorinity of pore fluid squeezed from core samples. Thus, we can expect a correlation in the amplitudes between chemical $\left(\mathrm{Cl}\right.$ and $\left.\delta^{18} \mathrm{O}\right)$ and thermal excursions.

Figure 2 demonstrates that Hole C0008A has a smaller (or negligible) chemical anomaly, whereas the thermal anomaly is much larger in Hole C0008A than in Hole $\mathrm{C} 0008 \mathrm{C}$. However, we should note that most $\mathrm{Cl}$ anomalies at $\mathrm{C} 0008 \mathrm{C}$ appear as a single point. This indicates that the measurement is aliased, and that the average width of the hydrate-bearing zone is thinner than the average $\mathrm{Cl}$ measurement interval $(5.5 \mathrm{~m})$. In that case, it is possible that the APC-T tool did not stay within the hydrate-bearing zone (and vice versa).

The temperature rise due to frictional heat at the time of penetration can be as large as $10 \mathrm{~K}$ (Expedition 316 Scientists, 2009). Figure 2 shows the maximum temperature recorded near the coring shoe (Tmax) and 


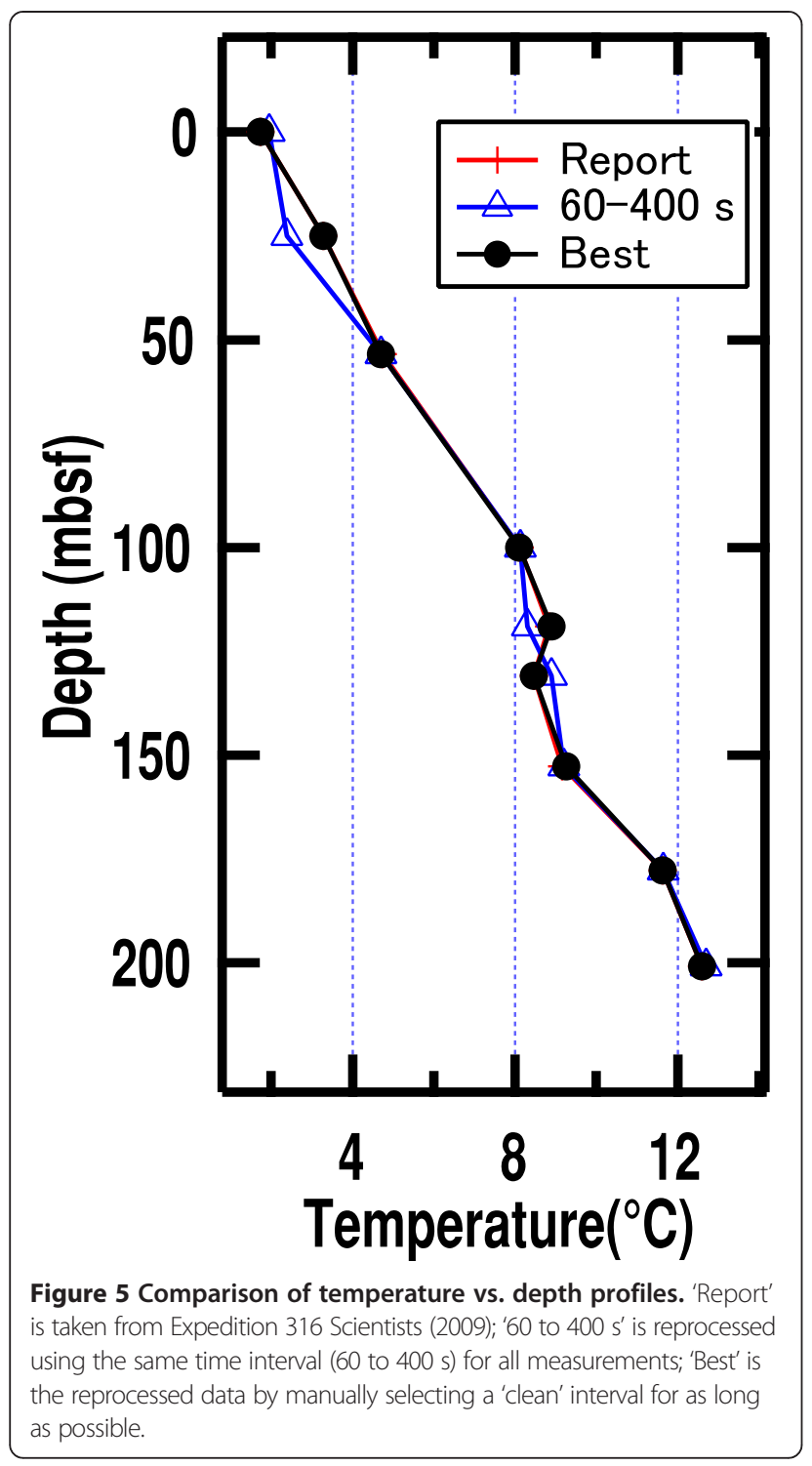

hydrate/gas phase boundary temperature (Tf) in Holes C0008A and C0008C. In some cases, the maximum temperature exceeded that of gas hydrate stability, which could have led to hydrate dissociation. However, this only means that the frictional heat energy is converted into gas internal energy. When all the excess heat is used up, the dissociation process simply stops, and further dissociation, leading to a decrease in the formation temperature from its original state, will never occur. If, on the other hand, no excess heat is used for hydrate dissociation, the temperature decay curve follows that of ordinary sediments. Thus, there is also no reason for excess heat to remain around the sensor, leading to a temperature increase. This is supported by the absence of correlation between Tmax and the residual temperature curves in Figure 2.
Firing the APC-T tool into a formation can alter the pressure around the shoe. Long et al. (2008) reported a pressure increase of 1 to $3 \mathrm{MPa}$ measured with downhole in situ pressure measurement tools (DVTP and T2P) during IODP Expedition 308. This suppresses hydrate dissociation or raises the hydrate/gas transition temperature (Tf) by up to $1 \mathrm{~K}$, based on the hydrate/gas phase transition diagram (e.g., Kvenvolden, 1993). Conversely, an APC$\mathrm{T}$ operation may increase pore space around the shoe, leading to a decrease in the pressure which promotes the dissociation of hydrates. A pressure reduction of about $3 \mathrm{MPa}$ is necessary to correspond to a temperature decrease of $1 \mathrm{~K}$. Although we cannot rule out these possibilities, maintaining such pressure anomalies is difficult because intervals with thermal anomalies include coarser grains with strong horizontal reflectors (Figure 1b; Expedition 316 Scientists, 2009), where the pressure decay by hydrological diffusion is normally faster than the thermal diffusion process.

\section{Apparent temperature decrease}

The friction-induced hydrate dissociation could disturb the thermal decay curve recorded in the APC-T logger, leading to the erroneous estimation of equilibrium temperatures (Teq). By constructing an axially symmetric 2D numerical model (Figure 6a), we created a synthetic thermal decay curve simulating the APC-T tool in the sediment that is initially heated by friction and then cooled by thermal diffusion and hydrate dissociation. The initial temperature is set at $0^{\circ} \mathrm{C}$ throughout the system. A maximum temperature rise (Tmax) is set at $12 \mathrm{~K}$, based on the observation. Assuming a Gaussian-shaped temperaturetime curve and a volume fraction of hydrate of $10 \%$, based

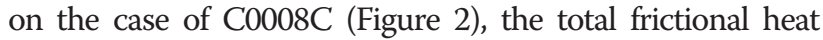
energy is estimated as approximately $40 \mathrm{~kJ}$ (see Appendix). The endothermic effect takes place only if the temperature exceeds a certain value (Tf, temperature of gas hydrate stability limit). Here, we set the value of $\mathrm{Tf}$ at $4 \mathrm{~K}$. In the case of $10 \%$ hydrate fraction, the latent heat of hydrate dissociation is $45 \mathrm{MJ}$ per $1 \mathrm{~m}^{3}$ of sediment (see Appendix). Since we do not know the reaction rate, we tested four different hydrate dissociation time constants $(2,5,50$, and $100 \mathrm{~s})$, which correspond to very rapid to slow reaction rates.

The calculated temperature decay curves are shifted downward by 1 to $3 \mathrm{~K}$ from the case without hydrate dissociation (thin curves in Figure 6b), although its amplitude and duration depend on the time constant of dissociation. Then, the extrapolation of Teq using 'tpfit' software was carried out using these synthesized datasets (Figure 6b). Although the curves for the first $10 \mathrm{~min}$ appear to be offset downward, the estimated Teq values are almost zero or slightly positive $\left(+0.3^{\circ} \mathrm{C}\right)$ for all cases. This indicates that the extrapolated temperature is 

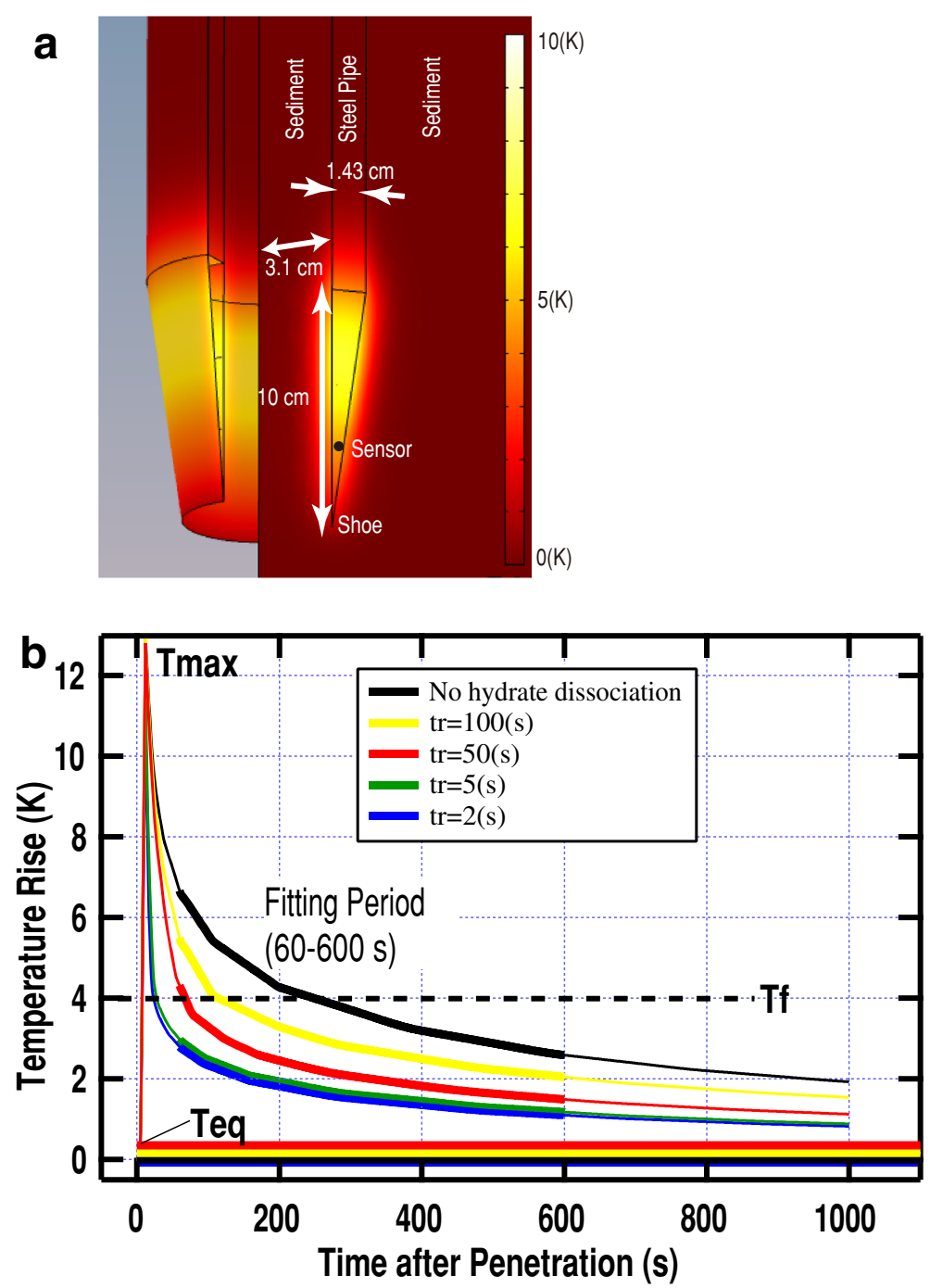

Figure 6 Configuration of finite element model in a 2D cylindrical system and temperature decay curves. (a) Configuration of finite element model in a 2D cylindrical system. Color image is an example of simulated temperature increase. (b) Temperature extrapolation results of numerically synthesized data, using the same software as used onboard DN Chikyu (tpfit3.exe). Teq, equilibrium (in situ) temperature estimated from temperature data between 60 and $600 \mathrm{~s}$ after penetration; Tf, threshold temperature above which the endothermic effect takes place in 2D simulation; tr, duration needed to dissociate all methane hydrate in the sediment (10\% volume fraction).

not seriously affected by heat absorption during the measurement.

\section{Combined effect?}

Although we cannot determine the mechanism yet, certain heat energy must have been lost from or added to the formation, corresponding to a temperature decrease/ increase of up to $1 \mathrm{~K}$, probably as a temporary phenomenon due to penetration.

Ruppel (1997) indicated that the temperatures at the BSR in Blake Ridge are anomalously lower, by 0.5 to $2.9^{\circ} \mathrm{C}$, than those predicted from its gas hydrate stability condition. Ruppel (1997) hypothesized that the capillary force in the fine-grained sediment inhibits the movement of pore fluid that is necessary for hydrate growth. However, Henry et al. (1999) rejected this hypothesis because the capillary effects require the pore size to be much smaller than in the Blake Ridge silty claystone. Henry et al. (1999) alternatively suggest that the system is not in thermodynamic equilibrium, to explain the offset of BSR position. We also doubt if the capillary force has any effect in our cases, because hydrate-bearing intervals are inferred in sand-dominant intervals.

Based on thermodynamic calculations, Buffett and Zatsepina (1999) suggest that hydrates can exist under a temperature of several degrees above its dissociation temperature, if the gas is supersaturated in the liquid. 
This possibly causes a sudden dissociation followed by a rapid cooling of sediments, although we have no evidence for such super-saturation of gas at Site C0008.

So far, we cannot suggest any single explanation for the observed thermal anomalies, although we strongly suspect that it is related to hydrate dissociation. A complicated interactive process may have occurred between the formation fluid and hydrates through advection along/across the formation or around the tool. More field data, as well as laboratory and numerical experiments, are required.

\section{Conclusions}

Thermal excursions were detected from in situ temperature measurements at IODP Site C0008 in the slope sediments in the forearc slope of the Nankai Trough off Kumano. The negative portion of the anomalies appears at almost the same depth interval as $\mathrm{Cl}$ and $\delta^{18} \mathrm{O}$ anomalies, which lead us to surmise that they are related to hydrate dissociation at the time of APC-T tool penetration. We carefully examined other possible mechanisms. Artifacts due to non-ideal penetration, such as multiple penetrations or poor contact between the tool and the formation, may result in large uncertainties in the extrapolated equilibrium temperatures, but after intensive investigation, we exclude such possibilities.

Even if the hydrates are dissociated by frictional heat upon penetration, they cannot absorb additional heat from the surrounding formation. Instead, the temperature decay curve after penetration will be disturbed by hydrate dissociation. This disturbance can cause an apparent misfit of the equilibrium temperature, but 2D finite element modeling considering the hydrate dissociation effect did not result in any significant difference in the extrapolated temperature.

Although we have no probable solution so far, we are sure that the negative thermal anomalies are a true feature caused as a transient effect by penetration. With further intensive study, we believe that in situ temperature profiling can be a useful tool for hydrate detection.

\section{Appendix: estimation of frictional heat energy and latent heat of hydrate dissociation}

The frictional heat energy vs. time envelope is given in the shoe section as a Gaussian function, with its peak value $\left(250 \mathrm{MW} / \mathrm{m}^{3}\right)$ set to produce a Tmax of $12 \mathrm{~K}$ and width $(1 \sigma)$ of $1 \mathrm{~s}$. The resultant total heat energy is calculated to be $40 \mathrm{~kJ}$ by multiplying the total heat energy density (which is equal to the peak energy, $250 \mathrm{MW} / \mathrm{m}^{3}$, by a definition of Gaussian function) and the volume of the shoe section $\left(160 \mathrm{~cm}^{3}\right)$. This energy is partitioned between the latent heat for hydrate dissociation and sediment temperature increase of $4 \mathrm{~K}\left(\sim 15 \mathrm{MJ} / \mathrm{m}^{3}\right)$ for a certain amount of sediment volume.
The latent heat loss due to hydrate dissociation in the sediment containing $10 \mathrm{vol}$ \% of pure hydrate was calculated to be $45 \mathrm{MJ} / \mathrm{m}^{3}$, using the latent heat of pure hydrate (500 kJ/kg; e.g., Ruppel, 1997) and its density $\left(910 \mathrm{~kg} / \mathrm{m}^{3}\right.$; Makogon, 1997). Comparison of energy input (40 kJ) with energy consumption $\left(\sim 60 \mathrm{MJ} / \mathrm{m}^{3}\right)$ gives a sediment volume of approximately $600 \mathrm{cc}$.

\section{Competing interests}

The authors declare that they have no competing interests.

\section{Authors' contributions}

MK and HF wrote the manuscript and created the figures. SG and TT discussed the cooling mechanism due to hydrate dissociation. $\pi$ checked the chemical descriptions. All authors contributed to the scientific discussions. All authors read and approved the final manuscript.

\section{Acknowledgements}

This work was partially supported by the Grant-in-Aid for Scientific Research 21107006 (MEXT). The authors are grateful to two anonymous reviewers for thorough reviews and constructive comments. Borehole data were provided by the Integrated Ocean Drilling Program (IODP). We are grateful to the crew and technicians of DN Chikyu and the Center for Deep Earth Exploration of the Japan Agency for Marine-Earth Science and Technology for the successful APC-T experiment and other operations during IODP Expedition 316.

\section{Author details}

${ }^{1}$ Kochi Institute for Core Sample Research of JAMSTEC, Nankoku, Kochi 783-8502, Japan. ${ }^{2}$ Graduate School, Kochi University (now at Misumi Group Inc.), Asakura 782-0003, Japan. ${ }^{3}$ Institute for Geo-Resources and Environment, National Institute of Advanced Industrial Science and Technology (AIST), Tsukuba 305-8567, Japan. ${ }^{4}$ Department of Chemistry, Biology and Marine Science, Faculty of Science, University of the Ryukyus, 1 Senbaru, Nishihara, Okinawa 903-0213, Japan.

Received: 29 June 2014 Accepted: 11 December 2014

Published online: 05 February 2015

\section{References}

Ashi J, Tokuyama H, Taira A (2002) Distribution of methane hydrate BSRs and its implication for the prism growth in the Nankai Trough. Mar Geol 187:177-191, 10.1016/S0025-3227(02)00265-7

Buffett BA, Zatsepina OY (1999) Metastability of gas hydrate. Geophys Res Lett 26:2981-2984

Bullard EC (1954) The flow of heat through the floor of the Atlantic Ocean. Proc Royal Soc London A 222:408-429

Expedition 316 Scientists (2009) Expedition 316 Site C0008. In: Kinoshita M, Tobin H, Ashi J, Kimura G, Lallemant S, Screaton EJ, Curewitz D, Masago H, Moe KT, the Expedition 314/315/316 Scientists (eds) Proc IODP, vol 314/315/316. Integrated Ocean Drilling Program Management International, Inc, Washington, DC, doi:10.2204/iodp.proc.314315316.136.2009

Heesemann M, Villinger H, Fisher AT, Tréhu AM, White S (2006) Data report: testing and deployment of the new APCT-3 tool to determine in situ temperatures while piston coring. In: Riedel M, Collett TS, Malone MJ, the Expedition 311 Scientists (eds) Proc IODP, vol 311. Integrated Ocean Drilling Program Management International, Inc, Washington, DC, doi:10.2204/iodp. proc.311.108.2006

Henry P, Thomas M, Clennell MB (1999) Formation of natural gas hydrates in marine sediments: 2 . Thermodynamic calculations of stability conditions in porous sediments. J Geophys Res 104:23005-23022

Kimura G, Moore GF, Strasser M, Screaton E, Curewitz D, Streiff C, Tobin H (2011) Spatial and temporal evolution of the megasplay fault in the Nankai Trough. Geochem Geophys Geosyst 12:Q0A008, doi:10.1029/2010GC003335

Kinoshita M, Moore GF, Kido YN (2011) Heat flow estimated from BSR and IODP borehole data: implication of recent uplift and erosion of the imbricate thrust zone in the Nankai Trough off Kumano. Geochem Geophys Geosyst 12:Q0AD18, doi:10.1029/2011GC003609

Kvenvolden KA (1993) Gas hydrates - geological perspective and global change. Rev Geophys 31:173-187, doi:10.1029/93RG00268 
Long H, Flemings PB, Dugan B, Germaine JT, Ferrell D (2008) Data report: penetrometer measurements of in situ temperature and pressure, IODP Expedition 308. In: Flemings PB, Behrmann JH, John CM, the Expedition 308 Scientists (eds) Proc IODP, vol 308. Integrated Ocean Drilling Program Management International, Inc, College Station, TX, doi:10.2204/iodp. proc.308.203.2008

Maekawa T (2004) Experimental study on isotopic fractionation in water during gas hydrate formation. Geochem J 38:129-138

Makogon YF (1997) Hydrates of hydrocarbons. Penn Well Pub Co, Tulsa, OK

Matsumoto R, Borowski WS et al (2000) Gas hydrate estimates from newly determined isotopic fractionation and $\delta^{18} \mathrm{O}$ anomalies of the interstitial waters: ODP Leg164, Blake Ridge. In: Paull CK, Matsumoto R, Wallace PJ (eds) ODP Sci Results, vol 164, Ocean Drilling Program. College Station, Texas, pp 59-66

Matsumoto R, Tomaru H, Lu H (2004) Detection and evaluation of gas hydrates in the eastern Nankai trough by geochemical and geophysical methods. Resour Geol 54:53-67

Moore GF, Kanagawa K, Strasser M, Dugan B, Maeda L, Toczko S, the Expedition 338 Scientists (2013) NanTroSEIZE Stage 3: NanTroSEIZE plate boundary deep riser 2. IODP Prel Rept 338. doi:10.2204/iodp.pr.338.2013.

Pribnow DFC, Kinoshita M, Stein CA (2000) Thermal data collection and heat flow recalculations for Ocean Drilling Program Legs 101-180. Institut für Geowissenschaftliche Gemeinschaftsaufgaben (GGA), Projekt: DFG Pr471/2, Datum: 6. Oktober 2000, Archiv Nr.: 0., pp 120-432

Ruppel C (1997) Anomalously cold temperatures observed at the base of the gas hydrate stability zone on the U.S. Atlantic passive margin. Geology 25:699-702

Shipboard Scientific Party (1992) Site 855. In: Davis EE, Mottl MJ, Fisher AT (eds) ODP Init Repts, vol 139, Ocean Drilling Program. College Station, TX pp 101-160, Doi:10.2973/odp.proc.ir.139.105.1992

Strasser M, Moore GF, Kimura G, Kopf AJ, Underwood MB, Guo J, Screaton EJ (2011) Slumping and mass-movement deposition in the Nankai forearc: evidence from IODP drilling and 3-D reflection seismic data. Geochem Geophys Geosyst 12:Q0AD13, doi:10.1029/2010GC003431

Tobin HJ, Kinoshita M (2006) NanTroSEIZE: the IODP Nankai trough seismogenic zone experiment. Sci Drill 2:23-27, doi:10.2204/iodp.sd.2.06.2006

Toki T, Higa R, ljiri A, Tsunogai U, Ashi J (2014) Origin and transport of pore fluids in the Nankai accretionary prism inferred from chemical and isotopic compositions of pore water at cold seep sites off Kumano. Earth Planets and Space 66:137, doi:10.1186/s40623-014-0137-3

Tomaru H, Matsumoto R, Lu H, Uchida T (2004) Geochemical process of gas hydrate formation in the Nankai trough based on chloride and isotopic anomalies in interstitial water. Resour Geol 54:45-5

Yamano M, Kawada Y, Hamamoto H (2014) Heat flow survey in the vicinity of the branches of the megasplay fault in the Nankai accretionary prism. Earth Planets Space 66:126, doi:10.1186/1880-5981-66-126

\section{Submit your manuscript to a SpringerOpen ${ }^{\circ}$ journal and benefit from:}

- Convenient online submission

- Rigorous peer review

- Immediate publication on acceptance

- Open access: articles freely available online

- High visibility within the field

- Retaining the copyright to your article

Submit your next manuscript at $\gg$ springeropen.com 